\title{
Preparation and physicochemical evaluation of transdermal aerosols containing ketoprofen
}

\author{
Fahimeh Ahmadi, Alireza Vatanara*, Esmaeil Moazeni, Fatemeh Hoseini, Majid \\ Darabi \\ Aerosol Research Laboratory, Department of Pharmaceutics, Faculty of Pharmacy, Tehran University of Medical Sciences,
} Tehran, Iran

*For correspondence: Email: vatanara@sina.tums.ac.ir; Tel: +982166980445

\begin{abstract}
Purpose: To prepare transdermal ketoprofen metered-dose aerosol formulations containing menthol and isopropyl myristate (IPM) as penetration enhancers and to evaluate their physicochemical and permeation properties.

Methods: Selected ratios of ketoprofen, ethanol, polyvinylpyrrolidone K30 (PVP K30, anti-nucleant), and penetration enhancers were mixed and filled into aluminum aerosol cans with hydrofluoroalkane134a as propellant. The physicochemical properties of the films, and their ex vivo permeation properties in rat skin were investigated over a 24-h period. Rat skin was exposed to a definite dose of each ketoprofen film to determine the quantity of drug in the receptor compartment over a 24-h period.

Results: All the transdermal formulations showed good integrity and film uniformity. Formulations with permeation enhancers presented higher rates of skin penetration compared to control formulations. Formulations containing 3\% PVP and 5\% IPM produced the highest permeation rates (Jss, 85.35 $\mu \mathrm{g} / \mathrm{cm}^{2} / \mathrm{h}$ ).

Conclusion: These results indicate that incorporation of antinucleant polymer and permeation enhancers in aerosols containing ketoprofen enhances aerosol stability and drug permeation through rat skin.
\end{abstract}

Keywords: Ketoprofen, Antinucleant, Permeation enhancer, Topical aerosol, Transdermal delivery

Tropical Journal of Pharmaceutical Research is indexed by Science Citation Index (SciSearch), Scopus, International Pharmaceutical Abstract, Chemical Abstracts, Embase, Index Copernicus, EBSCO, African Index Medicus, JournalSeek, Journal Citation Reports/Science Edition, Directory of Open Access Journals (DOAJ), African Journal Online, Bioline International, Open-J-Gate and Pharmacy Abstracts

\section{INTRODUCTION}

The therapeutic level of drugs after transdermal exposure has been extensively studied [1-3]. The stratum corneum is a major barrier to drug penetration through the skin. Since the lipid domain of stratum corneum is affected by chemical permeation enhancers, different chemical and biological enhancers that affect the lipid domain have been investigated [4-7]. Ketoprofen is a Non-Steroidal Anti-Inflammatory Drug (NSAID) which relieves inflammationinduced pain, as well as vascular headache and dysmenorrhea. It is usually administered through the oral or rectal route [8]. Gastrointestinal complications such as ulcerations, abdominal burning sensation and pain, are some common side effects of ketoprofen [9]. To avoid these side effects, transdermal formulations, such as ketoprofen cream and ketoprofen ointment, have been developed for periodontal disease and osteopenia [10,11]. Percutaneous absorption of ketoprofen cream formulation and its effect on osteopenia have been studied [10-12]. Furthermore, the efficacies of different ointment bases and a new derivative of soy lecithin have 
been investigated in the transdermal deliveries of drugs $[13,14]$. Indeed, investigations have been carried out on the effects of various topical formulations on different diseases, such as migraine, postoperative sore throat, and muscle soreness $[15,16]$. In recent years, transdermal metered-dose aerosols have been introduced as a new system of drug delivery to the skin. The advantage of transdermal aerosols over other topical routes of administration is the absence of any local irritation $[17,18]$.

The purpose of this study was to prepare some transdermal aerosol formulations of ketoprofen and investigate their skin penetration capacities in the presence of penetration enhancers.

\section{EXPERIMENTAL}

\section{Materials}

Ketoprofen was received as a gift from Iran Hormone Co., Tehran, Iran. Pure ethanol (99.7$100 \%$ ) and PVP K30 were purchased from Bidestan (Tehran, Iran) and Fulka, (Switzerland), respectively. In addition, 1,1,1,2-tetrafluorethane (HFA 134a) was kindly gifted from INEOS Flour, UK. Methanol and IPM were provided by Pars Daru (Tehran, Iran) and Sepidaj (Tehran, Iran), respectively.

\section{Formulation and preparation of metered-dose aerosol}

Metered-dose aerosol solutions were formulated by dispersing ketoprofen (as a filmforming polymer, PVP) and an enhancer in pure ethanol (Table 1). The compounds were mixed with a magnetic stirrer overnight to solvate the polymer. Thereafter, aliquots of the solutions were dispensed into aerosol containers (Bespak Europe Ltd., UK). A 63- $\mu \mathrm{L}$ valve was crimped on each container and the can was then filled with filtered HFA 134a. Ketoprofen concentrations were adjusted to $1.6-1.9 \mathrm{mg}$ per puff, and pure ethanol was set at $1.0 \%(\mathrm{w} / \mathrm{w})$. The latter allowed for reduction of negative effects on the vapor pressure and the release velocity of the liquefied propellant through the orifice. Each polymer film formation was tested by spraying it onto a clear plastic plate and allowing the solvent to evaporate.

\section{Optical microscopy}

The homogeneities of the solutions were observed using an optical microscope (Euromex, Netherlands) equipped with a camera system (Sony, Japan). The morphologies of the produced films were assessed before and after the films were filled into the cans. For this purpose, the formulation was sprayed and photographed.

Table 1: Composition of transdermal metereddose aerosol formulations

\begin{tabular}{lccc}
\hline Formulation & $\begin{array}{c}\text { PVP } \\
(\%)\end{array}$ & $\begin{array}{c}\text { IPM } \\
(\%)\end{array}$ & $\begin{array}{c}\text { Menthol } \\
(\%)\end{array}$ \\
\hline F1 & 5 & 5 & - \\
F2 & 7.5 & 7 & - \\
F3 & 5 & - & 5 \\
F4 & 7.5 & - & 5 \\
F5 & 7.5 & - & 5 \\
F6 & 5 & - & - \\
F7 & 7.5 & - & - \\
F8 & 3 & 5 & \\
F9 & 3 & 7 & \\
F10 & 3 & - & 2.5 \\
F11 & 3 & - & 5 \\
F12 & 3 & - & - \\
\hline
\end{tabular}

The contents of ethanol (40\%) and ketoprofen (5\%) were the same in all the formulations. Each of the formulations was made up to $100 \%$ with HFA $134 a$

\section{Preparation of skin membranes}

The in vitro study was performed by using fullthickness skins of 8-week-old male rats. The experimental protocols were approved by Institutional Review Board of Faculty of Pharmacy, Tehran University of Medical Sciences (ref no. 5074). The animals were handled according to EU Directive 2010/63/EU on the handling of animals used for scientific purposes [19]. Using a surgical blade, the skins were isolated by separating the underlying subcutaneous fat and connective tissue. The skins were kept frozen in a freezer at $-20^{\circ} \mathrm{C}$ until used. Prior to use, they were they were transferred to a room temperature setting.

\section{Drug permeation studies}

The skins were clamped in vertical Franz diffusion cells with a donor surface area of 3.8 $\mathrm{cm}^{2}$ per skin, and maintained in a water bath at $37^{\circ} \mathrm{C}$ [20]. Phosphate-buffered saline (PBS, 23 $\mathrm{mL}, \mathrm{pH}$ 7.4) was used to fill the receptor compartment. Temperature was set at $37^{\circ} \mathrm{C}$ throughout the 24-h experiment using a water bath. At the beginning of the diffusion experiments, 5 puffs of the ketoprofen 
formulation were applied to the exposed area of the skin. Each sample $(1 \mathrm{ml})$ was collected from the receptor compartment at $10 \mathrm{~min}$, and at 1, 2, 4, 6, 8 and $24 \mathrm{~h}$ post-dosing, and replaced with 1 $\mathrm{ml}$ of fresh PBS.

\section{High-performance liquid chromatography (HPLC)}

HPLC was employed for the determination of drug concentration in each sample. Separation was carried out with $4: 17(\mathrm{v} / \mathrm{v})$ ratio of phosphoric acid:methanol as a mobile phase at a flow rate of $1.2 \mathrm{~mL} / \mathrm{min}$ in an EC 250/4.6 Nucleodur 100-S $\mathrm{C} 18 \mathrm{ec}$ column. The column temperature was set at $40{ }^{\circ} \mathrm{C}$ and injection volume was $100 \mu \mathrm{L}$. The peak area of chromatogram obtained at $256 \mathrm{~nm}$ was taken as reference for determination of drug concentrations in the samples.

\section{Data computation}

The cumulative amounts of the drug that penetrated per unit surface area $\left(\mu \mathrm{g} / \mathrm{cm}^{2}\right)$ were analyzed as a function of time (h). The following formula was applied to calculate the in vitro skin permeation rate or steady state flux $\left(J_{s s}\right)$.

$J_{s s}=\Delta M / A \Delta t$

where $\Delta M$ is the amount of ketoprofen that penetrated through the skin within a defined time $\Delta t$, and $A$ is the diffusional area.

The cumulative amount of the absorbed drug in $24 \mathrm{~h}$ was also measured. The effect of each penetration enhancer was represented by an
Enhancement Ratio (ER), which was calculated as shown in Equation 2 below.

$E R=J_{s s} F / J_{s s} C$

where $J_{s s} F$ is the skin permeation of formulation with enhancer, and $J_{s s} C$ is the skin permeation of formulation without enhancer.

\section{Statistical analysis}

The data are presented as mean \pm standard deviation (SD). Differences between results obtained for formulations containing various excipients were statistically analyzed using Student's t-test with the aid of SPSS 16.0 statistical software. Differences were considered statistically significant at $p<0.05$.

\section{RESULTS}

\section{Characteristics of the formulations}

Tough films with smooth surfaces were produced by all the formulations. However, when examined under the microscope, all the films had some fine air bubbles.

The cumulative amounts of ketoprofen that permeated from the films through the rat skin over $24 \mathrm{~h}$ were calculated by HPLC. The cumulative amounts of the drug release for all formulations with enhancers were significantly $(p$ $<0.05)$ higher than for those without the permeation enhancers (Figures 1 and 2).

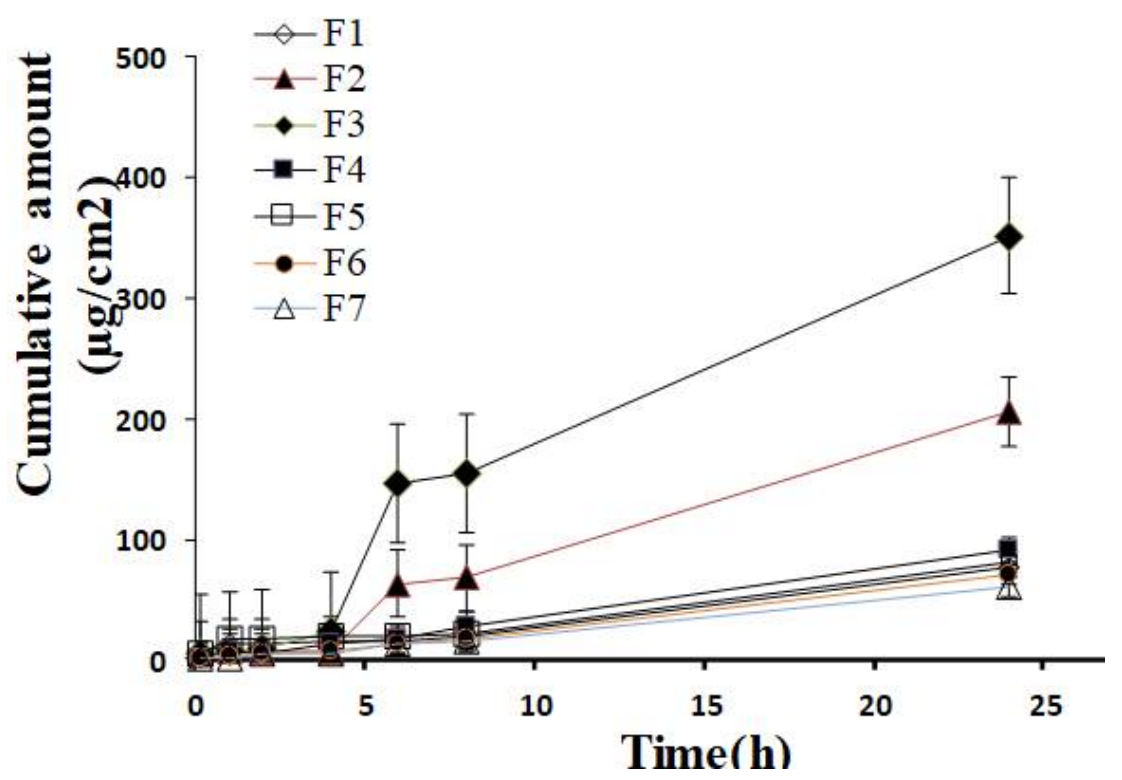

Figure 1: Permeation profile (mean \pm SD) of formulations prepared with 5 and $7.5 \%$ PVP $(n=3)$ 


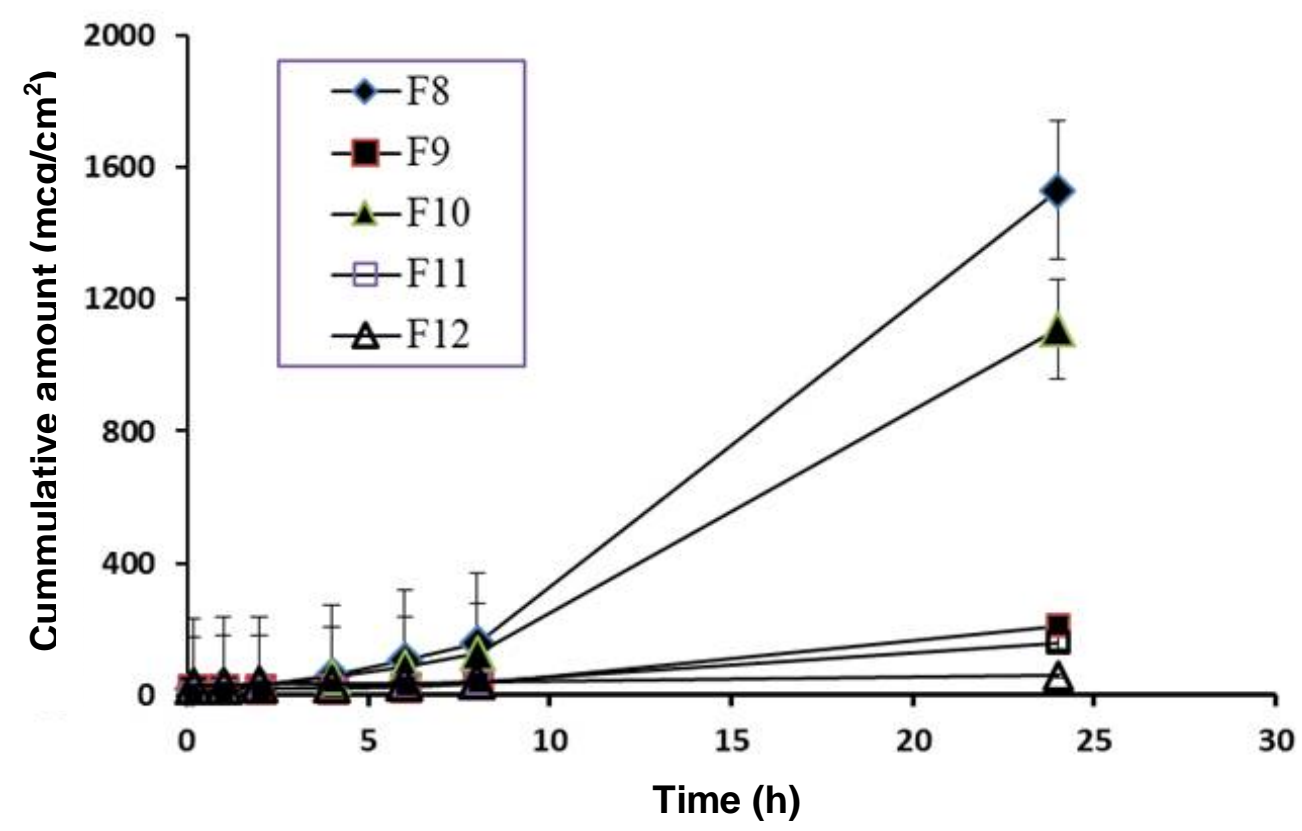

Figure 2: Permeation profile (mean $\pm S D$ ) of formulations prepared with $3 \%$ PVP $(n=3)$

Table 2: Permeation rate $\left(J_{s s}\right)$ and enhancement ratio $(E R)$ of formulations prepared with 5 and $7.5 \%$ PVP

\begin{tabular}{lcc}
\hline Formulation & $\mathbf{J}_{\mathbf{s s}}\left(\boldsymbol{\mu g} / \mathbf{c m}^{2} / \mathbf{h}\right)$ & ER \\
\hline F1 & $3.64 \pm 0.017$ & $1.10 \pm 0.026$ \\
F2 & $8.71 \pm 0.144$ & $3.24 \pm 0.033$ \\
F3 & $12.39 \pm 0.104$ & $3.75 \pm 0.046$ \\
F4 & $3.87 \pm 0.139$ & $1.44 \pm 0.035$ \\
F5 & $3.66 \pm 0.009$ & $1.37 \pm 0.018$ \\
F6 & $3.30 \pm 0.070$ & - \\
F7 & $2.68 \pm 0.030$ & - \\
F8 & $85.36 \pm 0.663$ & $79.38 \pm 0.683$ \\
F9 & $10.71 \pm 0.549$ & $9.96 \pm 0.566$ \\
F10 & $61.14 \pm 0.786$ & $56.86 \pm 0.81$ \\
F11 & $6.97 \pm 0.358$ & $6.48 \pm 0.369$ \\
F12 & $1.08 \pm 0.017$ & - \\
\hline
\end{tabular}

In the formulations with $5 \%$ PVP, F3 showed a significantly $(p<0.05)$ higher permeation rate than F1 (Table 2). Formulations with $7.5 \%$ PVP increased the permeation rate approximately as much as those of the formulations containing $5 \%$ PVP.

Drug release, in the presence of lower amounts of PVP, were evaluated for formulations F8 to F12, with PVP concentration at $3 \%$. As can be seen in Table 2, formulations with 3\% PVP produced significantly $(p<0.05)$ higher permeation than those with $5.0-7.5 \%$ PVP.

Among all the formulations, F8 which contained $5 \%$ IPM and 3\% PVP had the highest permeation rate. This formulation showed a drastic rise in the amount of ketoprofen that permeated through the rat skin.

\section{DISCUSSION}

PVP is a well-known inhibitor of drug crystallization in pharmaceutical formulations. Many researchers have studied the inhibition mechanism of PVP in aqueous suspensions or solid dispersions [21, 22]. Amorphous drugs are in a high energy state that causes increased solubility and consequently a high thermodynamic activity and penetration rate [22]. At high concentrations of PVP, this effect may be reduced because of the interaction between the drug and PVP [23]. Thus, drug release in the presence of lower amounts of PVP was studied on formulations F8 to F12, where PVP concentration was lowered to $3 \%$. This modification in the formulations resulted in a drastic rise in the amount of drug that permeated through the rat skin. Indeed, when the penetration enhancers were applied at the concentrations of $5 \%$ (for IPM) and $2.5 \%$ (for menthol), steady state flux reached values of 85.35 and $61.13 \mu \mathrm{gg} / \mathrm{cm}^{2} / \mathrm{h}$, respectively. Therefore, in these series of studies, an optimal level of film former was identified so as to ensure the highest drug penetration rate for each enhancer.

The presence of IPM or menthol in the films increased the flux of the drug, unlike in films without the enhancers. Calculation of $E R$ for comparing the permeation rates of the drug in 
the presence of the penetration enhancers revealed a considerable increase in the flux of the drug through the rat skin. The increased drug flux implies that the studied formulation would provide durable therapeutic effects. This enhancement in drug activity can be due to a number of factors, such as the kinetics of the enhancer release from the film, and the interaction between the enhancers and other components of the film. These factors may induce varied effects depending on the amounts of polymers and enhancers [23]. Moreover, the enhancing effect depends on the composition of the formulation and the physicochemical features of drugs [24].

Terpenes have been reported to increase the permeations of various groups of drugs, and amongst the terpenes, menthol enhances the penetrations of hydrophilic drugs $[25,26]$. The mechanisms involved in enhancement of drug penetration by terpenes include perturbations in the skin layer and lipid domains [27]. Various analogues of fatty acids have been studied as penetration enhancers [28]. Fatty acid esters generally affect drug permeation by increasing the fluidity of intracellular lipids [29]. In the present study, the penetration enhancers used, which are compatible with ethanol and HFA $134 \mathrm{a}$, were found to increase the penetration rate of ketoprofen after $8 \mathrm{~h}$. This suggests that within $8 \mathrm{~h}$, the enhancers produced optimum effects by positioning themselves between the phospholipid bilayers in the stratum corneum.

\section{CONCLUSION}

The improved duration of release of high concentration of ketoprofen seen in this study is made possible by the formation of satisfactory films with the aid of PVP as an anti-nucleant. The films containing 5\% IPM and 3\% PVP is capable of enhancing skin permeation of ketoprofen up to 79.38-fold in rats when compared with formulations without an enhancer. Thus, the formulations have a potential for transdermal delivery of ketoprofen in therapeutics.

\section{DECLARATIONS}

\section{Acknowledgement}

This study was funded and supported by Tehran University of Medical Sciences (TUMS). The authors would like to thank Pasteur Institute for providing the animals used in the study.

\section{Conflict of Interest}

No conflict of interest associated with this work.

\section{Contribution of Authors}

The authors declare that this work was done by the authors named in this article and all liabilities pertaining to claims relating to the content of this article will be borne by them.

\section{Open Access}

This is an Open Access article that uses a funding model which does not charge readers or their institutions for access and distributed under the terms of the Creative Commons Attribution License (http://creativecommons.org/licenses/by/ 4.0) and the Budapest Open Access Initiative (http://www.budapestopenaccessinitiative.org/rea d), which permit unrestricted use, distribution, and reproduction in any medium, provided the original work is properly credited.

\section{REFERENCES}

1. Ammar HO, Ghorab M, El-Nahhas SA, Kamel R. Design of a transdermal delivery system for aspirin as an antithrombotic drug. Int J Pharm 2006; 327: 81-88.

2. Changez M, Varshney M. Aerosol-OT Microemulsions as transdermal carriers of tetracaine hydrochloride. Drug Dev Ind Pharm 2000; 26: 507-512.

3. Evren AY, Özge I. Transdermal Spray in Hormone Delivery. Trop J Pharm Res 2014; 13(3): 469-474.

4. Lee PJ, Ahmad N, Langer R, Mitragotri S, Shastri VP. Evaluation of chemical enhancers in the transdermal delivery of lidocaine. Int J Pharm 2006; 308: 33-39.

5. Yano T, Higo N, Fukuda K, Tsuji M, Noda K, Otagiri M. Further evaluation of a new penetration enhancer (HPE 101). J Pharm Pharmacol 1993; 45(9): 775-778.

6. Doungdaw C, S.Kevin Li. Structure Enhancement Relationship of Chemical Penetration Enhancers in Drug Transport across the Stratum Corneum. Pharmaceutics 2012; 4: 71-92.

7. Williams AC, Barry BW. Penetration enhancers. Adv Drug Deliv Rev 2004; 56: 603-618.

8. Mehta DK., editor. Non-steroidal anti-inflammatory drugs In British National Formulary. 43rd edn. UK: British Medical Association; 2002; $p 482$.

9. Parfitt K., editor. Analgesics Anti-inflammatory Drugs and Antipyretics In Martindale, The Complete Drug Reference. 32nd edn. London: Pharmaceutical Press; 1999; pp 61-62.

10. Moretti MD, Gavini E, Peana AT. In vitro release and antiinflammatory activity of topical formulations of ketoprofen. Boll Chim Farm 2000; 139(2): 67-72.

11. Saeed UN, Razi UK, Muhammad A, Muhammad N, Misbah S, M. Naeem Q, Attique U, Ghulum M, Abdul M. Formulation development, evaluation and antiinflamatory effects of ketoprofen cream on rheumatoid arthritis patients. Int J Curr Life Sci 2013; 3(10): 132136. 
12. Lehman PA, Raney SG. In vitro percutaneous absorption of ketoprofen and testosterone: comparison of pluronic lecithin organogel vs. pentravan cream. Int $J$ Pharm Compd 2012; 16(3): 248-252.

13. Valenta $C$, Wanka M, Heidlas J. Evaluation of novel soya-lecithin formulations for dermal use containing ketoprofen as a model drug. J Control Release 2000; 63(1-2): 165-73.

14. Jaeckle E, Schaefer UF, Loth H. Comparison of effects of different ointment bases on the penetration of ketoprofen through heat-separated human epidermis and artificial lipid barriers. J Pharm Sci 2003; 92: 13961406.

15. Friedman MH, Peterson SJ, Frishman WH, Behar CF. Intraoral topical nonsteroidal antiinflammatory drug application for headache prevention. Heart Dis 2002; 4: 212-215.

16. Friedman $M H$, State NY. Migraine, tension-type headache and facial pain. A common intraoral etiology and treatment. J Dent 2002; 68: 24-26.

17. Jones SA, Reid ML, Brown MB. Determining degree of saturation after application of transiently supersaturated metered dose Aerosols for Topical Delivery of Corticosteroids. J Pharm Sci 2009; 98(2): 543-554.

18. Ozaki M, Minami K, Sata T, Shigematsu A. Transdermal ketoprofen mitigates the severity of postoperative sore throat. Can J Anaesth 2001; 48: 1080-1083.

19. European Commission [homepage on the internet]. Directive 2010/63/EU on the protection of animals used for scientific purposes [cited 2014 May 10]. Available from: http://ec.europa.eu/enviroment/chemicals/lab_ani mals/legislation_en.htm.

20. Makiko F, Naohide H, Kumi Sh, Kyoko W, Emi K, Mitsuo M. Effect of fatty acid Esters on permeation of ketoprofen through hairless rat skin. Int $J$ Pharmaceut 2000; 205: 117-125.

21. Lindfors $L$, Forssén $S$, Westergren J, Olsson $U$. Nucleation and crystal growth in supersaturated solutions of a model drug. J Colloid Interface Sci 2008; 325(2): 404-413.

22. Su YL, Guiduk Y, II WK. Effects of polymeric additives on the crystallization and release behavior of amorphous ibuprofen. J Nanomater2013; 2013: 1-7.

23. Taylor LS, Zografi G. Spectroscopic characterization of interactions between PVP and indomethacin in amorphous molecular dispersions. Pharm Res 1997; 14: 1691-1698.

24. Vaddi HK, Ho PC, Chan YW, Chan SY. Terpenes in ethanol: haloperidol permeation and partition through human skin and stratum corneum changes. J Control Rel 2002; 81: 121-133.

25. Narishetty STK, Panchagnula R. Transdermal delivery of zidovudine: effect of terpenes and their mechanism of action. J Control Rel 2004; 95: 367-379.

26. Inayat BP, $C$ Mallikarjuna $S$. Chemical penetration enhancers for transdermal drug delivery systems. Trop J Pharm Res 2009; 8(2): 173-179.

27. Jain AK, Narishetty STK, Panchagnula R. Transdermal drug delivery of imipramine hydrochloride. I. Effect of terpenes. J Control Rel 2002; 79: 93-101.

28. Mittal A, Sara UV, Ali A, Aqil M. Status of fatty acids as skin penetration enhancers-a review. Curr Drug Deliv 2009; 6(3): 274-279.

29. Doungdaw C, S.Kevin Li. Structure enhancement relationship of chemical penetration enhancers in drug transport across the stratum corneum. Pharmaceuts 2012; 4(1): 71-92. 